\title{
Debating Jomon Social Complexity
}

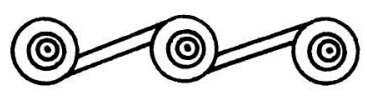

\author{
RICHARD PEARSON
}

\section{INTRODUCTION}

IN THIS ARTICLE I explore aspects of Jomon social complexity and examine three classes of artifacts that may be considered indicators of status differences: lacquer ornaments and vessels, elaborately decorated pottery vessels, and grave goods. Recent discoveries of artifacts and sites showing specialized production techniques, coordinated labor, substantial inputs of time, and ceremonial occasions have led archaeologists to explore the nature of Jomon societies and the general topic of social complexity. In addition to the discovery of complex lacquer ornaments and elaborately decorated pottery deposited in pits after what appears to be a single event, these include the construction of stone and wood monuments (Kobayashi 2002), exceptionally large villages with different areas for storage, ritual, and burial such as Sannai Maruyama (Fig. 1) (Habu 2002), and complicated storage facilities (Sakaguchi 2003).

Three aspects of Jomon hunter-gatherer life that set it apart in comparative perspective are the early dates for the beginning of the Jomon pattern and its long duration, the early onset of Jomon sedentism, and the development of cultivation. The long duration of the Jomon period, coupled with the environmental diversity of the Japanese islands, have permitted a wide range of cultural and social diversity, including a variety of settlement and subsistence strategies. With advances in AMS (accelerator mass spectrometry) dating and calibration, the beginning of the Jomon period is now placed around 13,500 to 14,000 cal B.C. Recent dating of the Jomon subperiods is given in Table 1.

The dating of the boundary between Jomon and Yayoi is now thought to be about 800 B.C., on the basis of AMS dates and new calibration studies (Harunari and Imamura 2004). Since the end of the Jomon period is not relevant to the discussions here-and is still debated-for our purposes, a rough date of mid-first millennium B.c. seems reasonable. The dating of the beginning of sedentism in Japan has been pushed back in recent years. Imamura states that the beginning of pottery and sedentary life in Japan began some 13,000 B.P. (2002:11-12)actually about 15,500 B.P. if the dates are recalibrated. Kelly (1992) refers to the

Richard Pearson is professor emeritus of anthropology in the Department of Anthropology at the University of British Columbia, Vancouver, Canada. He has also been appointed as senior research advisor, Sainsbury Institute for the Study of Japanese Arts and Cultures, Norwich, United Kingdom. 


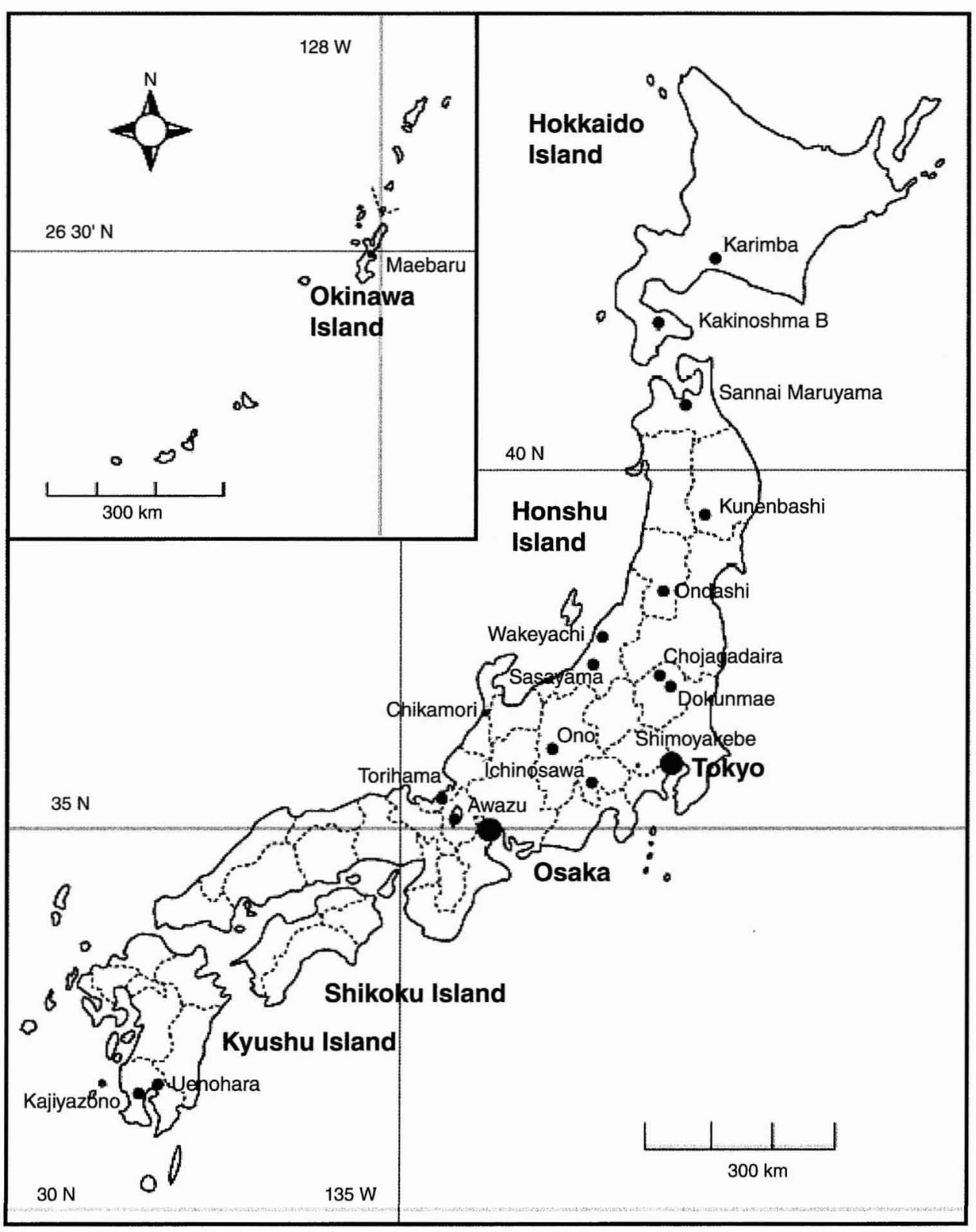

Fig. 1. Location of Jomon sites mentioned in the text.

push/pull hypotheses concerning the necessary conditions for sedentism: Resource abundance is said to pull groups to settle down, while resource scarcity and high population lead to expansion of the range of foods, more time spent in harvesting and processing, and sedentism. Most Japanese archaeologists consider both aspects: the pull of the abundance of nut-bearing trees in the postPleistocene deciduous forests and the push of the disappearance of large game 
Table I. Revised Chronology for Jomon of the Kanto and Chubu Areas

\begin{tabular}{lll}
\hline JOMON SUBPERIOD & \multicolumn{1}{c}{ CAL B.C. } & \multicolumn{1}{c}{ CAL B.P. } \\
\hline Incipient & $13,680-9250$ & $15,630-11,200$ \\
Initial/Earliest & $9250-5300$ & $11,200-7250$ \\
Early & $5300-3360 / 3500$ & $7250-5310 / 5450$ \\
Middle & $3360 / 3550-2580 / 2510$ & $5310 / 5450-4800 / 4460$ \\
Late & $2580 / 2510-1260 / 1230 / 1220$ & $4800 / 4460-3210 / 3180 / 3170$ \\
Final/Latest & $1260 / 1230 / 1220-(410)$ & $3210 / 3180 / 3170-2360$ \\
\hline
\end{tabular}

Note: Based on 158 dates, many analyzed after 1990 and recalibrated according to Stuiver et al. (1998). From Taniguchi (2001).

at the end of the Pleistocene (Okamura 2002). After 12,000 years B.P., sitesparticularly in Kagoshima Prefecture, such as Kajiyazono-display a set of stone tools for plant processing more similar to Jomon than to Palaeolithic: they include chipped adzes for digging, pit houses, and pottery (Shinto 2001). The new Jomon adaptation seems to occur with the spread of deciduous leaved nut-bearing trees in southern Kyushu and a climatic warming. Acknowledging that sedentism is a complex process rather than a threshold and that increased site size, the presence of houses, and dense concentrations of artifacts may be the result of reoccupation or repeated use of special purpose sites (Kelley 1992:50-57), it seems that sites in southern Kyushu dating to about 12,000 в.P. such as Uenohara 4 in Kagoshima Prefecture show many signs of sedentism, with ten houses occupied at one time and clearly defined paths between houses (Pearson 2006). These dates are roughly comparable to dates for the Pre-Pottery Neolithic of the Levant $(11,700 \mathrm{cal}$ B.P. to $8250 \mathrm{cal}$ B.P.), in which sedentism increased dramatically (Kujit and Goring-Morris 2002:362-377).

There has been an extended debate about whether Jomon people practiced cultivation. A current view is that from the beginning of the Initial Jomon period, a number of plants were cultivated, but they constituted a small proportion of the total diet (Matsui and Kanehara 2006). Bottle gourd (Lagenaria siceraria), perilla (Perilla ocimoides), shiso (Perilla frutescens), beans of Vigna species, burdock (Arctium sp.), and some kinds of goosefoot (Chenopodium) were found in the lake-bottom site of Awazu, Lake Biwa, Shiga Prefecture, dating from the beginning of the Initial Jomon. Buckwheat (Fagopyrum esculentum), rapes (Cruciferae), hemp (Cannabis sativa), and yam (Dioscorea) have been recovered from Early Jomon sites such as Torihama, Fukui Prefecture, and small quantities of rice and barley, barnyard millet (Echinochloa esculenta), foxtail millet (Setaria italica), and common millet (Panicum miliaceum) have been found in sites dating to the Middle Jomon and later. Cultivation is thought by Matsui and Kanehara to have started in the disturbed, enriched soil of midden areas. In addition, the tending of the edible chestnut, Castanea crenata, has been postulated (Matsui and Kanehara 2006:267-268). It is clear that cultivation did appear in the Jomon period, but it is equally clear that it remained a minor activity that did not contribute significantly to the growth of social complexity (Rowley-Conwy 2002:62). In fact, Hudson (1997) has argued that the rejection of full-scale agriculture was one characteristic shared by Jomon societies. The Jomon have often been compared with ethnographically 
recorded groups of coastal northwestern North America or California (Aikens and Dumond 1986; Nakamura 2002), both known for their relatively high population densities and food processing and storage technologies without dependence on cultivation.

Jomon people constructed animal traps, weirs, and site facilities such as streamside washing facilities. At certain times in their long history, Jomon people produced sophisticated, elaborate crafts, large two-story buildings, and wooden and stone henges. In some of the large buildings, particularly in eastern Japan in the Middle Jomon period, there is evidence of the use of a common unit of measurement of $35 \mathrm{~cm}$, thought by Fujita (1999) to facilitate construction by cooperating groups from different communities. Otahara $(2000: 108)$ has proposed that the Middle Jomon (c. 2,500 B.c.) six-post structure at Sannai Maruyama, Aomori Prefecture, is a monument for calendrical reckoning. The long side of the structure lines up with the sunrise on the summer solstice and the sunset on the winter solstice. He proposes that the six-post structure at the Chikamori Site, Kanazawa Prefecture, had the same function. Such places were designed to map out the yearly cycle and to permit local people to participate in the ceremonies of the cycle either by living at the site or coming to participate (Mizoguchi 2002:104). While there are many examples of stone circles (Kobayashi 2002), the Ono Stone Circle Site in the Kiso Valley, Nagano, is interesting because it yielded house sites suggesting that contemporary with the stone circle there were pit dwellings and elevated storehouses, the site being maintained by a local intermarrying group of about 400 persons who buried their ancestors in the stone circle site (Sasaki 2002).

Many writers regard the Jomon as primarily egalitarian. They contrast the Jomon period with the succeeding agricultural, stratified Yayoi society (Imamura $1996: 120)$. Habu, however, states that we need to reappraise the assumption of Jomon egalitarianism (2004:243).

Cultural anthropologist Hitoshi Watanabe proposed in Jomonshiki Kaisoka Shakai (Jomon Style Stratified Society, 1990) that Jomon society is part of a group of North Pacific coastal stratified societies. Basing his arguments on archaeological materials and ethnographic analogy, Watanabe noted that the nature of social stratification in Jomon is different from the stratification found in agricultural complex societies. According to Watanabe, in North Pacific coastal stratified societies the distinction lies between those engaged in big game hunting and those who were excluded from it. Northwest Pacific groups sought big game such as bears, sea mammals, and Pacific swordfish, each activity requiring special technology and ritual. He noted that wealthy persons had sophisticated ornaments and valuables from distant environments and mobilized collective rituals around stone circles and wooden pillar sites.

Although Watanabe does not give a precise definition of stratification, he stresses the vertical status distinction between those who hunt big game and those who are denied access to such activities. Since big game hunting did not provide food for basic subsistence, it could be said that its importance lay in the social reproduction of these groups. In sum, the elite controlled superior technology, mobilized the community into collective rituals, and had access to refined exotic luxuries as social badges, thereby controlling the means of social reproduction. Watanabe's treatment tends to be based on dramatic examples from the Middle 
Jomon and does not reflect the variability in sites and cultures of the Jomon period. However, he provides a way of thinking about the meaning of the rich Jomon material record. Timothy Earle's discussion of the emergence of new material media that were instrumental in the emergence of hierarchical structure during the Neolithic transition in Thy, Denmark (2004), resonates with Watanabe's discussion of Jomon refined technology. Earle notes that "individuals and groups engaged cultural media with particular characteristics of scale, permanency, and control" (112) to mark their social difference. The degree of social differentiation is not addressed by Watanabe but has been considered by Price $(1995,2002)$ and Fitzhugh (2003). Price (1995) stated that complexity involves features such as widespread interaction and aggregation, increased sedentism, refined technology, wide resource utilization, and intensified subsistence practices. He noted that hunter-gatherer societies may innovate technologically ("horizontal intensification") without creating hierarchical structures through "vertical intensification" (143). Fitzhugh refers to social differentiation (variation in horizontal and vertical dimensions of status and power): "The horizontal dimension can be tracked with reference to patterned variation in tool assemblages, features, activity locations, and evidence of craft specialization. The vertical dimension is measured through variation in the quality and quantity of materials across populations (at several scales from household to village to region)" (15).

Craft specialization, elaborate ritual, and the inclusion of luxury grave goods with members of social groups that cross-cut groups based on age or gender are thought to be hallmarks of social complexity. In the following sections, I look for evidence of inequality or restricted access and attempt to elucidate what the patterns of distribution might mean in terms of hierarchy or other social subgrouping. In the final discussion, I comment on Jomon social complexity and some of the factors that contributed to its emergence.

\section{CASE STUDIES}

\section{Lacquer}

The complicated nature of harvesting, refining, mixing, coloring, and applying lacquer raises broad questions about Jomon social life. At present, trees produce for about ten years, each year yielding about 0.5 liter per tree (Mori 1989:82, $89,90)$. The trees must be eight to ten years old before they yield extra lacquer for harvesting in July and August. The raw lacquer must be mixed with oil from egoma (Perilla frustescens), which was cultivated from the Middle Jomon, before it can be used. Lacquer trees do not form thick stands in the wild, nor do wild trees produce substantial quantities of sap, suggesting that they had to be tended even in early times (Iizuka 2000:93,169-170). It is thought that by the Early Jomon, some villages may have tended fields of lacquer trees. It also appears that Japanese lacquer may be genetically different from mainland lacquer, as determined by the DNA analysis of seeds from the Sannai Maruyama site by plant geneticist Yoichiro Sato (Iizuka 2000:39). This could mean that the Japanese species-and the associated techniques for use-were not introduced from the Asian continent. The uses of lacquer for complex combs (made by fastening the teeth to the back of the comb) and coating textiles (angin) are certainly different from those found 
on the Asian continent. It appears that lacquer may have spread from east to west within Japan and that it had both utilitarian and ritual uses. By the time of the Kamegaoka Culture of Late and Latest Jomon, there appears to have been sponsored craft production and producers and consumers, judging from the large number of small spouted vessels (Sasaki 1997:127), which are designed to be held in two hands and must be turned to the recipient, suggesting ritual consumption of a special drink (Iizuka 2000:128).

Two kinds of red coloring material were used by Jomon artisans: hematite and mercuric oxide. Kenjo (1983) found that the coloring material of lacquered combs and hair ornaments is mostly mercuric oxide, while hematite (bengara) was used on ceramics. Hematite has been found on stone palettes on which it was ground, and apparently it was kept in receptacles such as clam and abalone shells. It was exchanged over long distances and is known to have been important in religious ritual (Iizuka 2000:15,26). Black coloring was produced by iron hydroxide. When it is found in concentrations over $3000 \mathrm{ppm}$, most archaeologists consider that it was intentionally applied (Kenjo 1983:291). Lacquer was often used with another precious material-asphalt-which occurred naturally in some Tohoku regions (northern Honshu Island). In some cases, the bottom of a vessel was treated with asphalt and its upper part was coated with lacquer.

Lacquer finds are difficult to quantify because they come from rare wet sites. Whereas lacquer was previously well documented from Early Jomon sites such as Torihama, it is now known from Initial Jomon sites. From Initial to Early Jomon, finds of lacquer are relatively rare and consist of lacquered fabric and wooden vessels. The Kakinoshima B site, Hokkaido, yielded an Initial Jomon ceremonial grave with lacquer-decorated twined textile (angin) placed near the postulated location of the upper arms and legs (Fig. 2). (Bone preservation was minimal.)

Layer $\mathrm{V}$ of Kakinoshima B was occupied in the Initial Jomon period. It yielded five pit houses and 162 burials. Radiocarbon dates for red and black lacquer objects from this site are around 7000 B.C. (Abe 2001). About 12,000 small lumps of red ocher were also recovered from areas of burned soil in the site. It appears that the soil was burned in the process of oxidizing the ocher (Tsuboi 2001). Lacquer technology in Incipient Jomon is already fully developed, suggesting that the tradition is older than anticipated earlier.

From Initial to Early Jomon, finds of lacquer are relatively rare and consist of lacquered fabric and wooden vessels. Miura (2002) states that at that time, people in southern Hokkaido were exchanging goods with Tohoku and were probably in contact with the Asian continent.

The Early Jomon Ondashi site, Yamagata Prefecture, yielded six ceramic bowls with red and black decoration and perforations around the rim. Their consistent shape and decoration suggest that they had a specific ritual purpose (Yamanashi $2002: 52,53)$.

A recent discovery from the Wakeyachi site, Kurokawa-mura, Niigata, dating to the first half of the Late Jomon (about 4000 years ago) emphasizes the importance of lacquer in the Japan Sea coastal region, in addition to Hokkaido, Tohoku, and the Kanto. About 40 artifacts were recovered. Pouring vessels were particularly notable; they have also been found in Saitama and Gumma Prefectures. Fashioned from wild cherry wood, they are round bottomed, spouted, and have handles. A flat-bottom bowl with decorated rim was also recovered. Ornaments include a composite comb, earrings, and pendants made of twined cord 


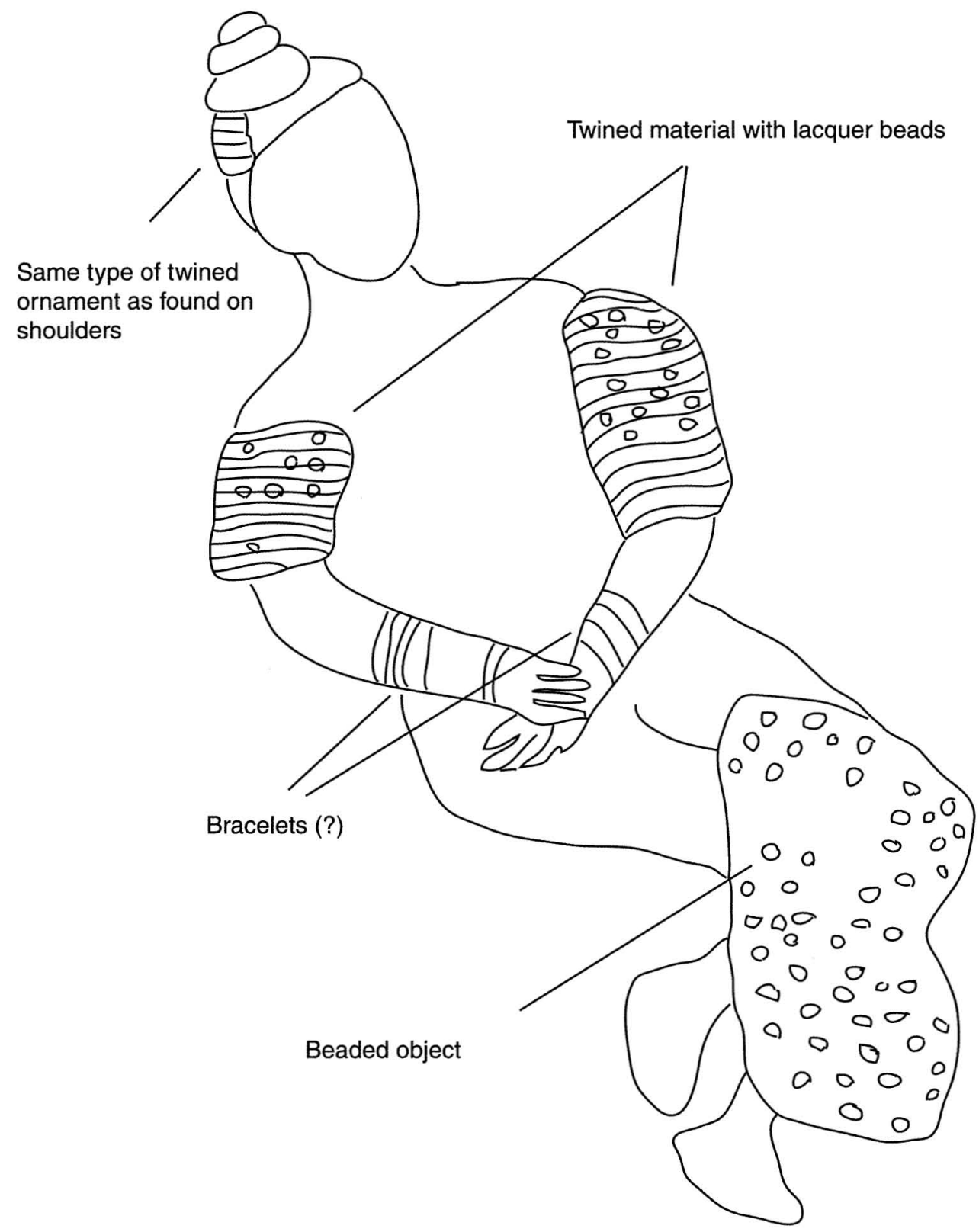

Fig. 2. Reconstruction of a grave with lacquer-decorated twined textile and 12,000 small lumps of red ocher. Kakinoshima B Site, Initial Jomon Period, Hokkaido (c. 7000 B.c.). Redrawn from Abe (2001: 13).

(Ito 2002a,b). The Shimoyakebe site, Tokyo, a wet site dating to Late and Latest Jomon, yielded ten lacquered bowls, thought to be used in hunting rituals. Pottery bowls for evaporating the water from newly harvested lacquer, identified by a residue of lacquer in the bottom, were also found (Chiba 2000:30).

The peak of lacquer development in southern Hokkaido was in the Late and Final Jomon Periods. Thirty sites are known, yielding objects such as combs with 
separate teeth attached individually to the spine of the comb, ornaments, wooden objects, pottery and figurines. Miura concluded that there is continuity between Jomon lacquer production and the lacquer of the Ainu (2002). The Late Jomon burial area of the Karimba Site, Eniwa City, Hokkaido, yielded 37 grave pits, of which 22 contained grave goods. Three particularly rich graves contained lacquered combs, bracelets, earrings and necklaces, a head ornament, and amber and steatite beads including curved pendants (magatama) (Uwaya and Sato 2000a,b). It has been suggested that the ornaments belonged to females. Two graves with 15 and 19 items, respectively, and their bottoms covered in red ocher, are thought to mark the graves of shamanesses (Fig. 3) (Uwaya 2000). There is a question as to whether all of the lacquer objects were made in Hokkaido or came from Honshu.

Given the complexity of the techniques of lacquer harvesting and preparation, specialists may have been involved. However, since the work was probably restricted to the summer when the lacquer could be extracted and applied, the specialists probably worked for only part of the year. Ethnoarchaeological examples of lacquer or resin technology among Asian hunter-gatherers are rare. Gianno's study (1990) of resin extraction from Dipterocarp trees among the Semelai people of Pahang, Malaysia, presents a situation that appears to be different from the Jomon case. Although resin is different from lacquer, its collection is similar, involving wounding the tree and collecting the liquid material in containers. It

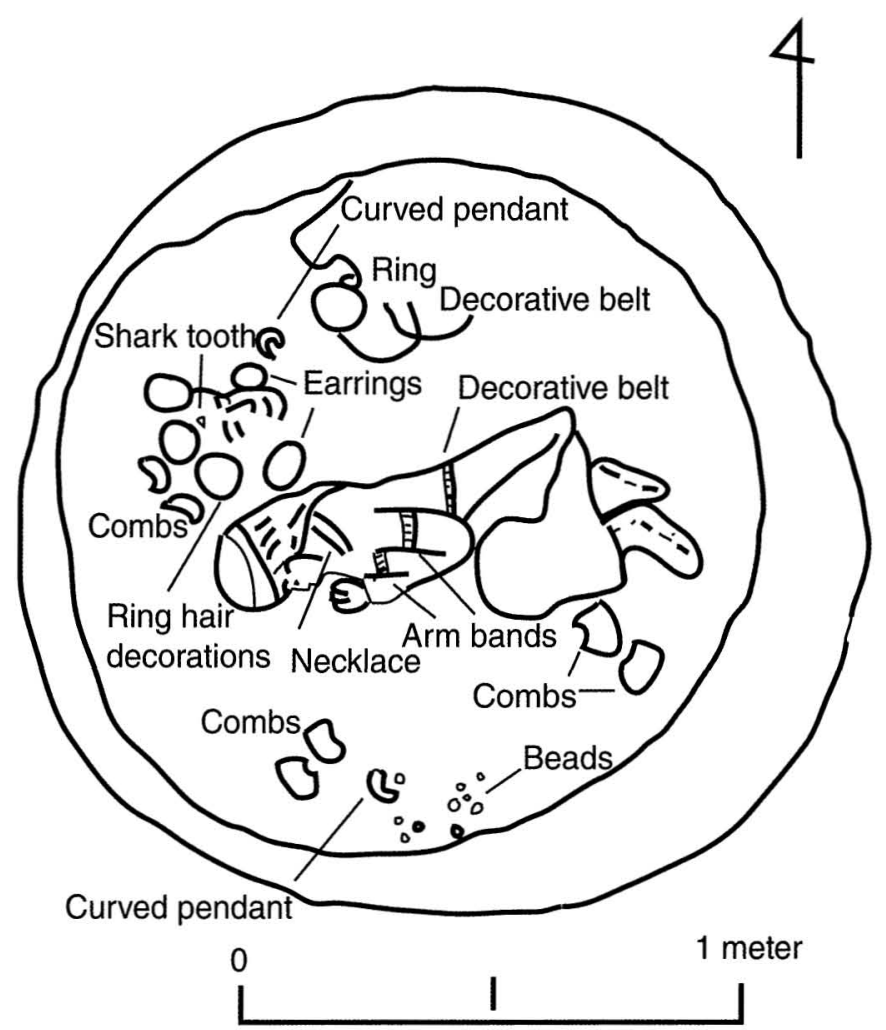

Fig. 3. Grave of shamanesses (?) showing combs, bracelets, earrings, head adornment, amber and steatite beads. Karimba Site, Late Jomon Period, Hokkaido (1500 B.c.). Redrawn from Uwaya (2000:28). 
was gathered by small groups who had no special status and was sold to itinerant traders. The Semelai did not treat lacquer as a prestige good, nor was access to it restricted to elite people. They used it for utilitarian purposes, in contrast to the Jomon people, who added special colors and applied it to precious items. The resin was traded, however, to middlemen who sold it as an expensive luxury good (Stargardt 2000:357-360).

In the Jomon case, the complexity of its preparation and its use for ornamentation suggests that its use was restricted. Many lacquer items are for serving food and drink and for adornment, such as composite combs. Some of the recently discovered Late Jomon burials in which it occurs have been interpreted as belonging to religious specialists.

\section{Elaborate Pottery}

Jomon pottery is famous for the elaborate hand-modeled shapes and surface treatments found in some areas and time periods. Since kilns are absent, it is inferred that the pottery was fired in bonfires. It is thought that the potters were part-time specialists. Studies of pottery temper have confirmed that vessels were exchanged among villages (Habu and Hall 1999, 2001), and there is some evidence that pottery-making villages distributed their wares to satellite villages (Pearson 2004:65). Watanabe (1990:138-139) provides several examples from different sites of individual Jomon house sites or burials that contained unusual pottery or ornaments. Can his approach be expanded to examine trends within whole sites or assemblages? It is very difficult to derive a clear picture of the number of very elaborate pieces from a single site or their spatial distribution. Such information might shed light on the role of the elaborate pottery and whether its distribution indicates the existence of a clearly defined, restricted group or class of consumers. Often, remarkable specimens are gathered into published compendia of masterpieces that exhibit striking artistic imagination, but no clues are offered concerning intra- or intersite distribution.

In the section below there are some examples of variability in whole-site assemblages, without regard to intrasite distribution patterns. The topic of Jomon doki sosei ron (composition of Jomon pottery assemblages) has been investigated for several decades (Fujimura 1983, 1999; Kaneko 1999). In the Angyo assemblages of the Late Jomon in the Kanto region (which surrounds Tokyo City), 95 percent of the pottery consists of coarsely decorated deep jars, while 5 percent is finely decorated, such as elevated dishes and shallow bowls. Fujimura (1999) grouped vessels in the Tohoku region according to function, which was determined by size, surface treatment, and ratio of height to mouth diameter. In the Final Jomon Kunenbashi site, Iwate Prefecture, a sample of 1314 pots was analyzed according to decoration and volume. Coarse (sosei) pottery comprised 52.5 percent of the assemblage, being mostly deep jars (fukabachi) and regular jars (hachi). Within the fine pottery (47.5 percent), most of the pots were shallow bowls and narrow-necked jars (tsubo). Other pottery forms were jars with elevated feet, shallow jars with feet, and pouring vessels. Over half of the total assemblage consisted of small vessels of under 1 liter in capacity. Most of the vessels of more than 5 liters capacity were coarse, deep jars (Fujimura 1999:36-37). Ueda (1999) notes that in the Late and Final Jomon, form and function seem to be tightly associated. In the Middle Jomon Katsusaka pottery, however, there is less variability 


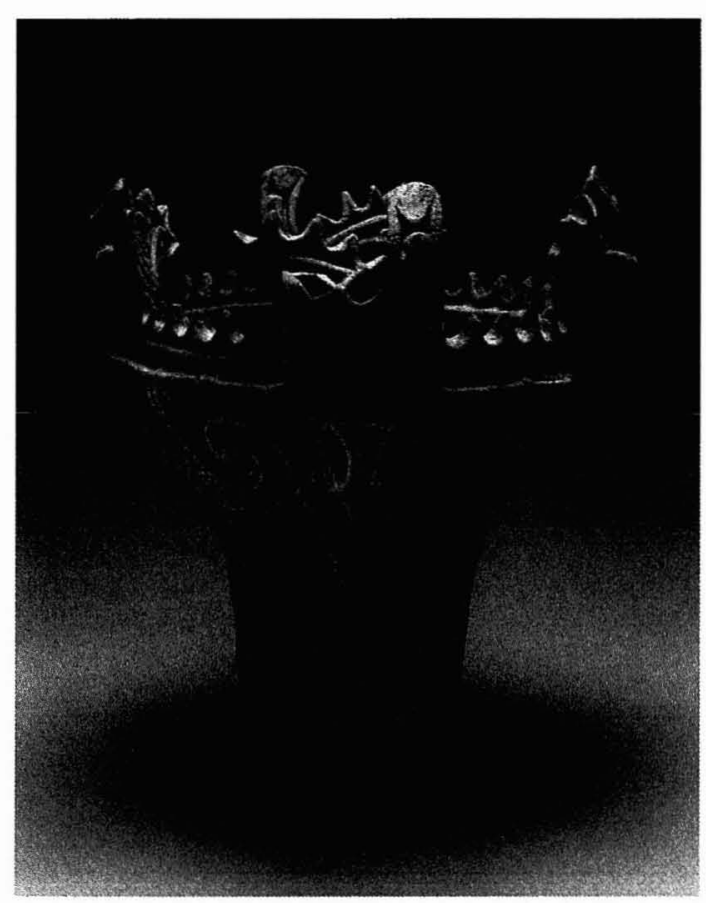

Fig. 4. Middle Jomon vessel, Sasayama Site, Niigata Prefecture. Courtesy of the Tokamachi City Board of Education.

in shape, most vessels being deep jars; it may be that function is indicated by different decorative motifs. The analyses mentioned above distinguished between large rough jars and fine serving vessels but did not examine the question of restricted social access to different types of vessels by considering spatial distribution and associations.

Distribution studies of specific kinds of Jomon pottery in sites must take into account site formation processes. Kobayashi (1974) identified several patterns of pottery disposal, two of which-Pattern A (Fukiage Pattern) and Pattern D (Heiwadai Pattern) - are characterized by the disposal of many unbroken pots, either in abandoned houses (A) or trash heaps, pits, or ditches (D). He proposed that there was a specific season for the disposal of old pottery, which likely occurred before spring shellfish collecting. He also proposed that deposition may have been a single event. Were ceramics with specific motifs or spectacular decor used by the general population or was use of them restricted? If elaborate pottery was spatially restricted within sites or associated with larger or more elaborate site features, it is possible that such pottery belonged to elites.

Although there are many huge reports of Jomon site excavations, since they are usually preliminary in nature it is not easy to disaggregate tabulated data to pursue particular problems of association. I provide four case studies of the context of spectacular Jomon vessels selected for special treatment by the excavators. I suggest that the spatial segregation of elaborate sculptural deep jars in particular may indicate that the pots were used in feasting and ceremonial displays. In the small 


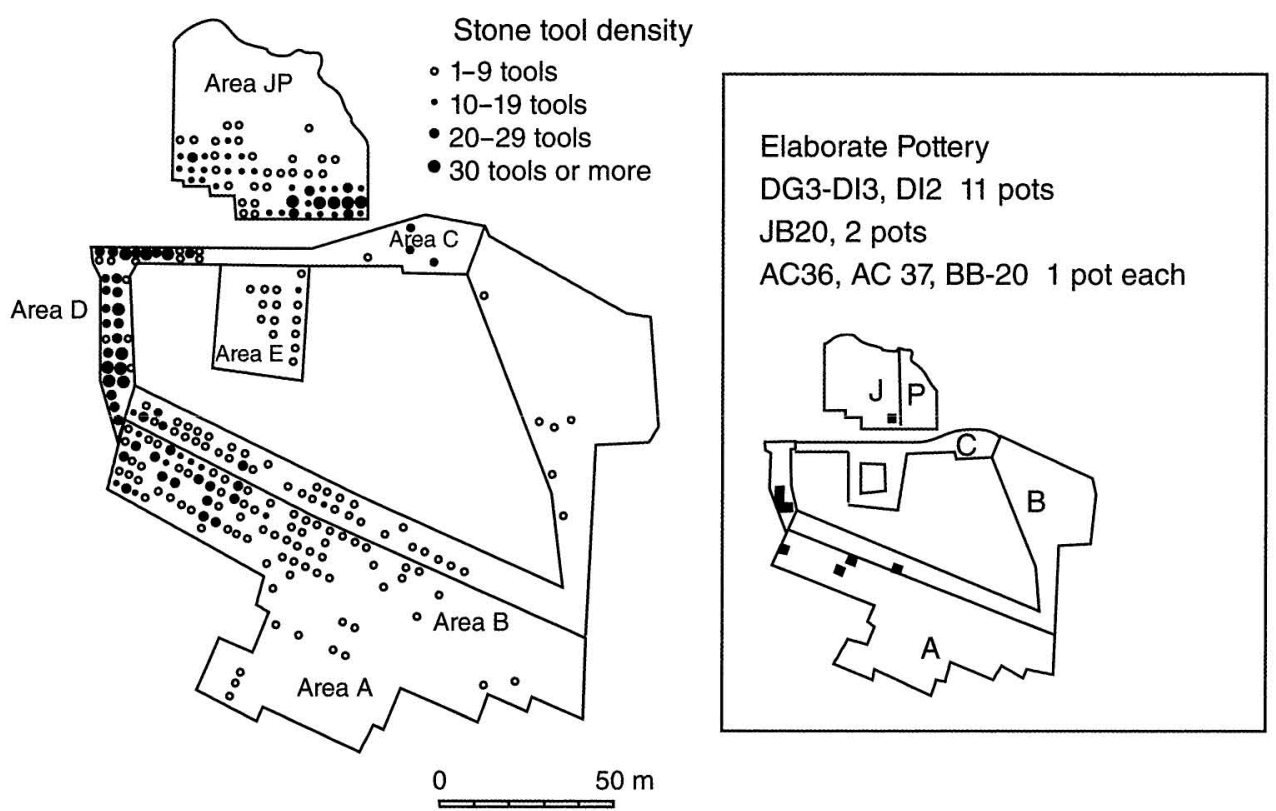

Fig. 5. Distribution of stone tools and fine pottery vessels, Sasayama Site, Niigata Prefecture, Middle Jomon period. Prepared from data presented in Niigata Ken Tokamachi Shi Kyoiku Iinkai (1998).

sample of four Middle Jomon sites in central Japan, which seem to display Kobayashi's Pattern A (Fukiage) disposal pattern, it appears that large elaborate vessels were buried near specific houses in one part of the site soon after use. However, the houses were not particularly large or elaborate. In two casesSasayama and Ichinosawa-figurines and stone tools were relatively dense in the area of disposal; and in one case-Ichinosawa - they were buried together.

Sasayama - The Sasayama site is located at Nakajo, Tokamachi City, Niigata Prefecture. It is situated on a terrace about $60 \mathrm{~m}$ above the Shinano River, which flows from the Central Alps to the Sea of Japan. A total area of $15,460 \mathrm{~m}^{2}$ was excavated from 1980 to 1985 and a report was published in 1998 (Niigata 1998). The site consists of a horseshoe-shaped cluster of 112 fireplaces, 6 pits, and 39 jar burials dating from the middle and later half of Middle Jomon to the early part of Late Jomon (about 4500 to 3500 B.P.). It was excavated in eight irregular zones: $\mathrm{A}, \mathrm{B}, \mathrm{C}, \mathrm{D}, \mathrm{E}, \mathrm{JP}, \mathrm{KL}$, and LR. Middle Jomon remains were recovered mostly from A, B, C, D, and JP. Remains of 1080 Jomon vessels were recovered. Of the total, 230 were reconstructable or the total shape could be postulated.

The site is famous for its elaborate Jomon pottery of the Umataka Kaen type (the so-called flame pottery), with cockscomb-style castellations and spiral and linear patterns made with raised clay bands and the Okan (crown-style) pottery, which has four prominent decorated castellations (Fig. 4).

The flame pottery is found in about 150 sites from the upper and middle reaches of the Shinano River (Niigata 1998:19). Sasayama has yielded the most specimens of the flame-rimmed deep jars (16) of any site excavated and four of 


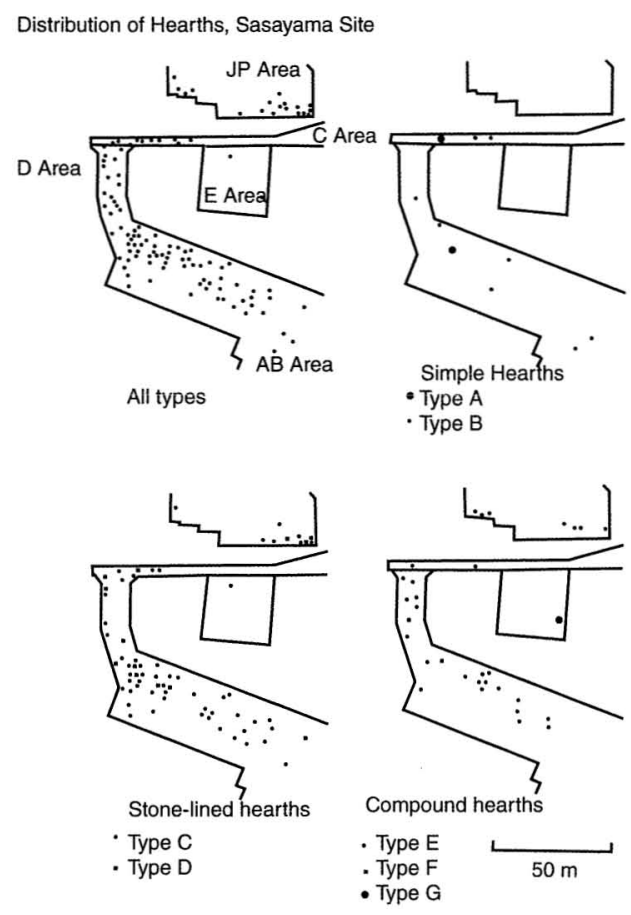

Elaborate Pottery
DG3-DI3, DI2 11 pots
JB20, 2 pots

AC36, AC 37, BB-20 1 pot each

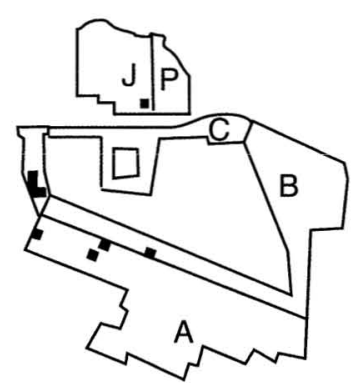

Fig. 6. Distribution of hearths and fine pottery vessels, Sasayama Site, Niigata Prefecture, Middle Jomon period. Prepared from data presented in Niigata Ken Tokamachi Shi Kyoiku Iinkai (1998).

the crown-type deep jars. The location of all of the pottery vessels within each $4 \mathrm{~m}^{2}$ unit is provided and the distribution of major artifact classes is given in tables and distribution maps (Figs. 5, 6).

Eleven of the 16 flame pots occurred in Area D, in a small group of $4 \mathrm{~m}^{2}$ excavation units, DG 3 to DI 3, and DI 2, while two each occurred in separate areas A (AC36, 37) and $\mathrm{J}(\mathrm{JB} 20)$ and one in $\mathrm{B}(\mathrm{BZ} \mathrm{30).} \mathrm{In} \mathrm{addition,} \mathrm{three} \mathrm{of} \mathrm{the} \mathrm{four}$ crown vessels occurred in DH 2 and DI 2. D is the smallest excavation area, comprising $510 \mathrm{~m}^{2}$, or 3.3 percent of the excavation area. Photos of the excavation show that the flame vessels seem to have been buried intact (Niigata 1998: pl. 131-134). They were lying on their sides, a position different from upright burial jars or jars associated with complex stone-lined hearths. No flame vessels or others of the elaborate types designated as Important Cultural Properties (as part of the national cultural heritage administration system) were used to build the complex hearths. Two vessels, Nos. 138 and 139, were buried near Hearth 14 in Area D. All of the elaborately decorated vessels and most of the others have soot and burned residue on the inside. In fact, most of the many reconstructed vessels also have soot and residue, concluded to have come from cooking.

What is the distribution of this most elaborate pottery in relation to the distribution of other types of artifacts (Fig. 7)?

The concentration in Area D is surrounded by hearths of the simple and stonelined types, but there is no close association with compound hearths, which are 
Distribution of clay artifacts, Sasayama
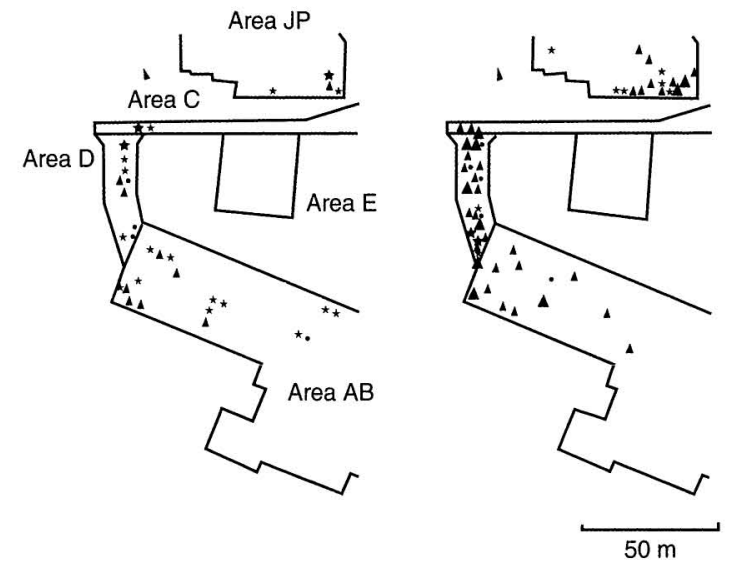

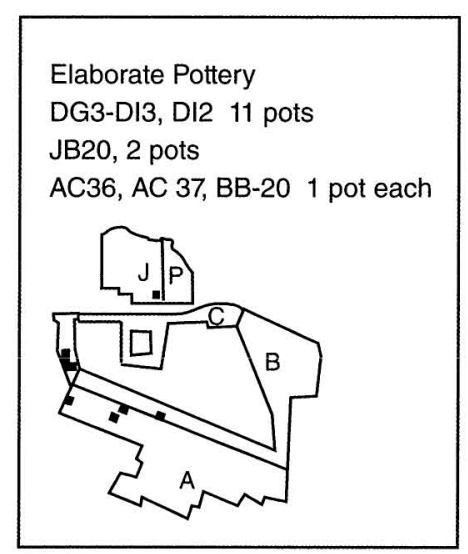

* Clay figurine (1 specimen)

* Clay figurine (2 specimens)

- Triangular figurine (1 specimen)

- Triangular figurine (2-4 specimens)

Triangular clay cylinder

Fig. 7. Distribution of clay artifacts and fine pottery vessels, Sasayama Site, Niigata Prefecture, Middle Jomon period. Prepared from data presented in Niigata Ken Tokamachi Shi Kyoiku Iinkai (1998).

the most elaborate. The concentration of vessels in Areas J and D shows close association with two of the three areas of high stone tool density. The third area of stone tool density in Area $\mathrm{C}$ is in an area of limited excavation; therefore the lack of elaborate pottery could be due to a sampling problem. Clay figurines of two types are relatively dense around the area of the concentration of vessels in Area D. In summary, the concentration of 70 percent of the vessels (14 out of 20) in one area is spatially associated with stone-lined hearths and stone tool and figurine density, but the pots were disposed of in separate pits. The pots were found in parts of the site that showed a high concentration of daily activities.

Chojagadaira - Sixteen elaborate vessels were found buried in an abandoned flask-shaped food storage pit at the Chojagadaira site, Otahara City, Ibaragi Prefecture. The site is semicircular in shape, with a diameter of $150 \mathrm{~m}$. The types were Niigata flame-type pottery, the Tohoku Jojoji Type, which resembles flame pottery, and a highly decorated local pottery. Ebihara (2003) notes that it is customary to bury garbage from daily activities in such pits and that the pots were "unburnable garbage" (moenai gomi) (2003:19). The pit was $1.4 \mathrm{~m}$ deep, with a bottom diameter of $2 \mathrm{~m}$. Once again, the distribution is concentrated.

Dokunmae - A number of exceptionally decorative vessels from the Dokunmae site, Hokkitsu Village, Gumma Prefecture, dating to the Middle to Late Jomon (roughly 3000 to 1500 B.C.), show that the deep jars may have been used individually, in separate houses. Approximately 20 percent of the site, yielding 28 pit houses and 274 pits, was excavated in 1996 (Hokkitsu 2001). The site yielded a relatively large number of flame-style pots, which resemble the flame pottery of 


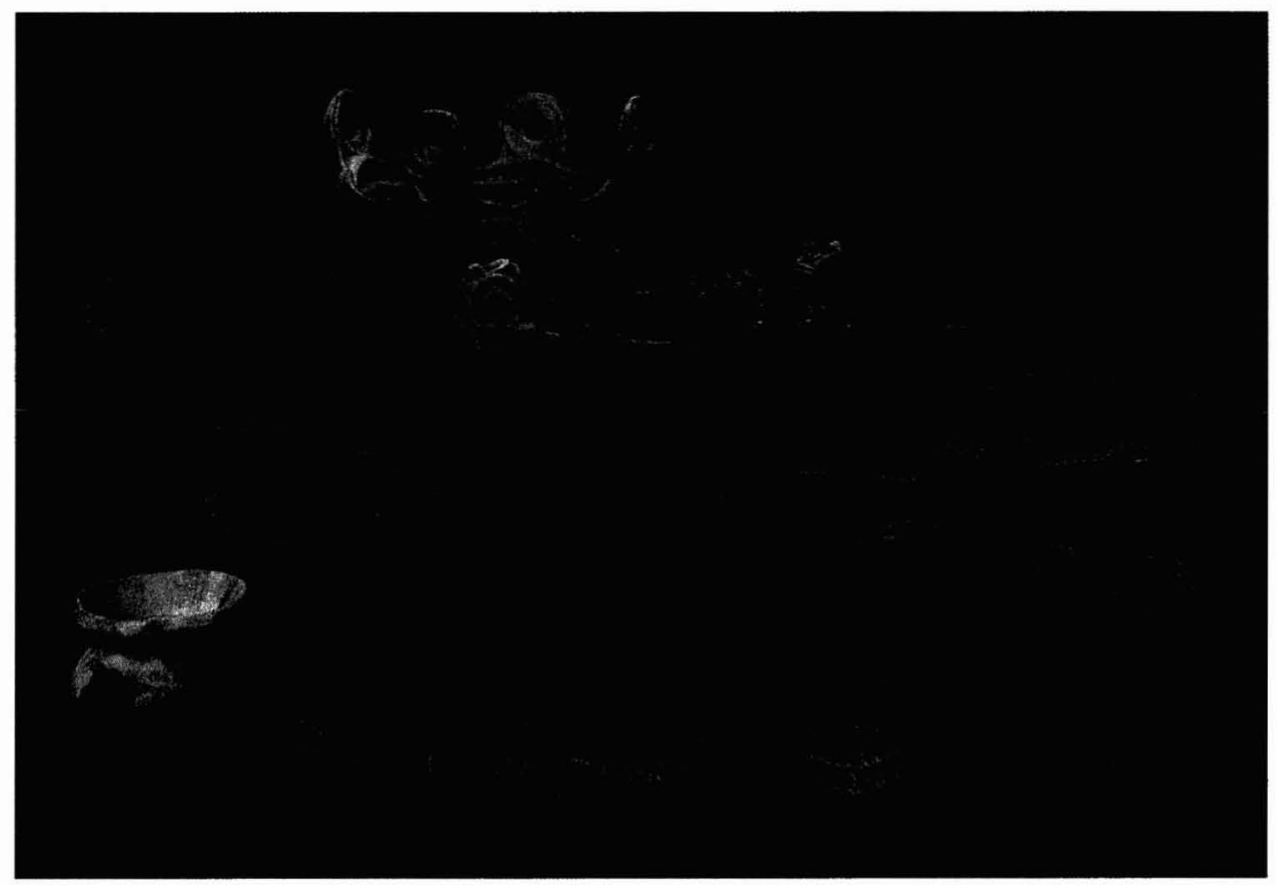

Fig. 8. Elaborate pottery vessels, Dokunmae Site, Middle Jomon period, Gumma Prefecture. From Hokitsu Mura Kyoiku linkai 2001 (frontispiece). Courtesy Shibusawa City Board of Education.

Niigata; since it has distinctive traits, it is referred to as flame-style related (kaenkei). This type has been found in the 15 sites in the upper middle reaches of the Tone River.

Although the color photo of the famous Dokunmae pots in the site report (Fig. 8) does not identify each vessel, nine of the ten could be found in the report. Most were found singly in small earth pits. Three specimens were associated with House 14, while one vessel was found in House 18 and one was in a pit near its edge. The distribution is concentrated, with five of nine (55 percent) being found in or near two houses (Fig. 9).

Ichinosawa - Ichinosawa is located in Sakaigawa Village, Yatsushiro-gun, Yamanashi Prefecture. Two houses out of five (Nos. 5 and 11) and four refuse pits yielded 176 artifacts, including 31 pottery vessels as well as figurines and stone tools (Yamanashi 2002:46-48). The number of Middle Jomon refuse pits is not given; all told, 100 pits were recovered from various periods within the Jomon.

In the small sample of four sites, the elaborately decorated pottery vessels were found to be concentrated in one area of the site near a small number of houses associated with daily living. The vessels were found intact or in very large fragments, which suggests burial soon after use. They were not used for burial jars or for making facilities such as hearths or pavements, nor do they appear to be associated with public architecture or burials. While they are grouped into sets in archaeological reports and for designation as cultural properties and they share stylistic similarities, they were not buried together, and there is nothing to suggest 


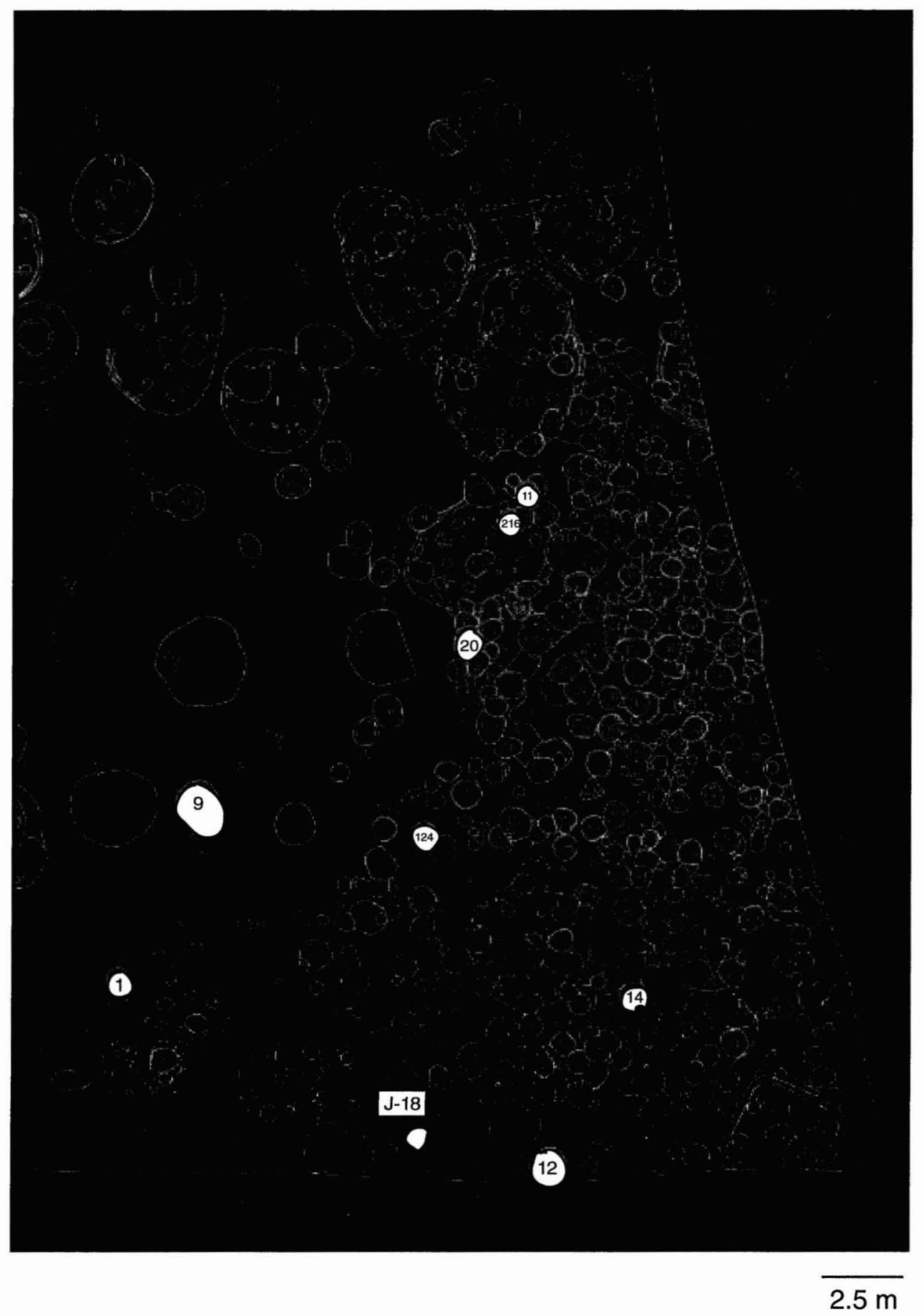

Fig. 9. Distribution of fine pottery vessels, Dokunmae Site, Middle Jomon period, Gumma Prefecture. Adapted from Hokkitsu Mura Kyoiku Iinkai (2001: fig. 202). 
that they were all used together in ritual sets, as ancient Chinese bronzes were. It appears that the vessels were buried after feasting or display. Since the associated houses are not conspicuously different from others, the feasting seems to have been on a domestic rather than public level (Weissner 2001:125), of the alliance and cooperative type in Hayden's classification (2001:38). Since the vessels are buried singly or in small groups in small pits, it seems unlikely that they were used in pan-village feasts, such as those sponsored by Big Men in Melanesia. An intensive study of the intra- and intersite distribution of elaborate vessels would be of great interest.

\section{BURIAL DATA}

While the lacquer and ceramics seem to be objects of luxury production, their archaeological context does not seem to indicate that they were used by a segregated social class. The study of social hierarchy from burial data may shed some light on the degree of hierarchy occurring in Jomon societies. Some burial data have been studied from the point of view of hierarchy and inequality. Skeletal preservation is poor because of acidic Japanese soils. In many cases, a burial is recognizable only from the outline of the burial pit. Some clues have been gained by examining trends in nonperishable grave goods such as stone and ceramic artifacts. Nakamura (2000) examined trends in a sample of 373 sites, all of which had grave goods. He grouped the burial data into three periods. In Period 1 (Incipient and Initial Jomon), he found that in some sites up to 20-30 percent of the graves had offerings that were usually items of daily use, such as deep jars, arrowheads, scrapers, and stone awls. There were very few ornaments such as shark's teeth and shell pendants. In Period 2 (end of Initial to Middle Jomon), ornaments such as jade slit earrings, shell bracelets, clay earrings, antler ornaments, and stone rods appear, along with lacquer-painted shallow bowls. There is more diversity than in Period 1. The rate of graves with grave goods ranges from 2 to 30 percent. In Period 3 (Late and Latest Jomon), Nakamura found age and sex differences in the nature of grave goods. About 10-30 percent of the burials had items of daily use, while 10 percent had ornaments and luxury items. There were more cases of luxury goods with children than previously. He concluded that inequality seems to exist in Period 3 in Hokkaido and northern Tohoku. Because he gives the total number of artifacts of each category in all of the sites for each region rather than the number of cases in which they occur, it is impossible to follow trends in the number of burials displaying certain kinds of grave goods. In a second paper (2002), Nakamura found that grave goods were included with juveniles in 17-25 percent of all cases in Hokkaido and the Kanto in the Final Jomon and that in the Final Jomon Kamegaoka Culture, burials interpreted as elite had different types of burials and grave goods.

In Ikeda's (2000) study of 526 Jomon sites, about 50 percent of the occurrences of grave goods were found in Latest Jomon. In Incipient Jomon, there were two possible cases of headbands. In Initial and Early Jomon, there were 31 and 63 cases, respectively, primarily of jade slit ring earrings, mostly in Fukui Prefecture and eastern Japan. In Middle and Late Jomon, there were 76 and 94 cases, respectively, mostly of stone beads and pendants. From these two studies there is no evidence of repeated redundant expressions of high status in tightly associated classes 
of artifacts. Evidence of a class of people with badges transcending age and sex seems to be limited to the Final Jomon.

Ikawa-Smith noted that the large Late Jomon kanjodori burials with embankment and ditch surrounding an internal burial mound of southern Hokkaido were built for local elites, but these communal graves did not show a "concentration of wealth and power, ritual or otherwise" (1992:85).

\section{DISCUSSION}

\section{The Nature of Jomon Social Complexity}

From the introductory remarks and case studies given above, Jomon people can be seen to have engaged in the part-time specialist activities of lacquer processing and the making of ceramic masterpieces from an early date. Yet the distribution of luxury goods in burials and sites does not seem to indicate the presence of hereditary elites. What is the nature of Jomon social complexity, and how do Jomon societies compare with other hunter-gatherer societies? We should expect a wide range of types and degrees of complexity within Jomon subcultures. The general discussion of hunter-gatherer complexity is becoming more focused and specific (Sassaman 2004). While this organizational complexity may involve complex divisions of labor in large communities, it leaves open the question of social inequality and the degree of sustainable hierarchy. Habu, in her book Ancient Jomon of Japan $(2004: 15,16)$, distinguishes between general cultural complexity, which includes organization complexity in settlement and subsistence systems, and a more formal definition of complexity. She concludes that organizational complexity reached its peak in the Middle Jomon in eastern Japan, while social complexity seems to have increased until the Final Jomon. These trends were governed by long-term changes in the types of available resources and their spatial distribution, as well as nonenvironmental factors such as technological developments, an increase or decrease in population density or pressure, the adoption of plant cultivation, and other types of environmental management, trade/exchange of critical resources, and changes in social relations, including the development of social alliances or warfare. The second type of complexity, which distinguishes complex hunter-gatherers from affluent hunter-gatherers, can be seen in Jeanne Arnold's study, which stresses sustained power by leaders to recruit labor from nonkin (Habu 2004:15, 16). This power is seen as the distinguishing characteristic of complex hunter-gatherers from affluent hunter-gatherers. Arnold's study of shell bead currency making among the Chumash of the California Channel Islands confirmed that the labor of nonkin in widespread communities was controlled by Chumash chiefs (Arnold 2001).

It has been common to assume the existence of status-based, internally ranked hierarchies when cultural complexity is discussed. Several Japanese authors have adopted the model of transegalitarian society proposed by Hayden (1995). In a review article concerning Jomon settlement and society, Takahashi (2001) pointed out that Jomon communities in both eastern and western Japan showed inclinations toward stratification, primarily in the Late and Latest Jomon periods. Such trends could be seen in communal construction projects, distributions of grave goods, and the production of luxury artifacts. He explored tribal societies of 
North American Indians to find relevant models of leadership for the Jomon period and concluded that in Late and Latest Jomon, large construction projects of wooden pillars would have required long-term planning and managing complex intercommunity relations by entrepreneurs in transegalitarian societies (2001:6970). According to Mizoguchi (2002), however, the cognitive world of the Jomon people consisted of layers of systems of humans, plants, animals, and imaginary categories and meanings, metaphorically bound together and made interchangeable by notions of cycle and regeneration. Activities such as hunting and gathering and ceremonies followed one another instead of being organized at the same time; therefore Jomon society did not need coordinators who were given permanent high status. Mizoguchi's critique seems to parallel the ideas of Price (1995) cited above-that there may be an increase in behavioural components without an increase in vertical integrating mechanisms.

The notion of aggrandizers has been critiqued on general grounds as being too simplistic and deterministic (Pearson 2005). Moreover, there are important alternative models to those of aggrandizer-entrepreneurs. Binford (2001:463) found that "hunter gatherer groups with high subsistence diversity and sociocultural complexity did not tend to be status based, internally ranked hierarchies. Instead they used age graded secret societies and other social forms to partition society into units that provide institutionalized services such as supplying wives, organizing funeral rites, or arranging periodic ritual events. The idea that complexity always results in the division of leadership into elite or privileged persons and the disenfranchised is a vestige of linear evolutionary projectories."

In their discussion of the Pre-Pottery neolithic of the Levant, in which cultivation, intensive collecting, hunting, and sedentism are clearly recognizable, Kujit and Goring-Morris (2002:420) found no convincing evidence for central hierarchy characterized by the existence of hereditary elites or architectural and skeletal evidence for the existence of interpersonal warfare. They prefer to acknowledge the existence of hierarchical and egalitarian relations in middle-range societies in general and to recognize the importance of social cohesion and collective identity (422). In their study of the LBK early Neolithic inhabitants of northeast Belgium, whose social complexity has also been a matter of debate, Kelley and Cohen (1989) found evidence of cooperation in defense among several villages, village specialization in flint blade and ground stone adze production, and some village specialization in ceramic production (production of fine ceramics may not have been common to all villages). They concluded that there were "growing but still inchoate data indicating that LBK society was more complex and organized than the traditional picture of egalitarian, autarkic villages" (173), but they did not find close correspondences to stereotypical big men or chiefdom societies.

Particular groups of hunter-gathers who emerged in resource-rich areas in the European Mesolithic and the Archaic period in North America stored large quantities of food when it was temporally overabundant. The degree of social complexity of these people has been debated. Marquardt noted that some groups might be "sophisticated in politics, knowledgeable in ecology, conversant with plant ecology and acquainted with far off lands, but might not be socially differentiated, hierarchic, redistributive, sedentary, or populous" (1985:83). As mentioned earlier, Arnold (2001:4) reserves the term "complex hunter-gatherers" for "groups in which leadership and social status are traditionally strictly located and 
leaders have substantial, renewable control over the labor of numerous nonkin." Multicommunity authority over the production and distribution of bead making was her most important criterion.

While most hunter-gatherers are organized into small mobile groups or bands, some hunter-gatherers, including some Jomon groups, lived in larger communities characteristic of tribal societies. Some Jomon groups occupied a peculiar place in tribal societies, since they were apparently sedentary but did not rely on agriculture. Thus it is useful to examine tribal societies, particularly ones that possibly practiced some cultivation along with hunting and gathering. Such comparisons expand the range of comparison beyond Pacific coastal groups such as the peoples of California or the Northwest Coast. While Fried (1975) considered tribes to be an aberrant form of social organization that occurred in very specific secondary contexts created by state expansion, other writers have called our attention to archaeological examples of tribal organization that arose in the absence of states. Parkinson $(2002: 6,7,9)$ notes that tribes were a dominant social form for several thousand years following the end of the Pleistocene. There have been many comparisons with Pacific coastal groups (Aikens and Dumond 1986; Koyama and Thomas 1981) but very few with eastern North American groups, despite the fact that eastern North American forests share many features with the deciduous forests of eastern Japan. North American comparisons with the Jomon often stress maritime adaptations, yet many Jomon people lived in sedentary inland communities. In the southeastern United States, evidence for long-distance exchange of prestige goods, warfare, and monumental construction indicate that band-level society was transcended some 6000 years ago (Yerkes 2002:268). There were North American tribes prior to European contact, and they ended before the indigenous development of state-level societies in these regions. The concept of tribe "deals with some degree of institutionalized social integration beyond the level of extended family unit or band" (Parkinson 2002:1). Without becoming hierarchical, tribal societies have social segments of roughly similar scale and composition that replicate themselves at varying levels within tribal societies, key characteristics being fission and fusion.

Fowles (2002:15-24) notes that the decision making in tribes is consensus based, situational, and unstable. Villages are autonomous; however, during times of warfare or religious crisis, societies that are otherwise egalitarian or tribal may take on structural qualities more similar to chiefdoms. These features seem to apply to various Middle to Latest Jomon communities. Yet the eastern North American cases show some strongly divergent aspects in settlement patterns.

The most obvious comparison with Jomon monument building and ritual might be made with the Hopewell Culture, in which elaborate burial ceremonialism is displayed in mortuary facilities often located away from settlements in a manner similar to Jomon stone circles and other monument sites, suggesting that they served to bring together people from a number of communities. The Hopewell people have been the subject of conflicting models of interpretation (Yerkes 2002) that resemble the debates about the significance of cultivation in the Jomon period. In one model they were sedentary swidden farmers, living near large, vacant ceremonial centers. Although some researchers propose that around 1000 B.C. the Hopewell gradually domesticated several weedy plants, which led to changes in economic and social organization and communal sharing gave way to 
household accumulation, according to Yerkes there is no evidence for this subsistence shift.

A different view is that the Hopewell were mobile and dispersed, yet well integrated through an elaborate ceremonial complex. The exotic goods that were once cited as evidence that Hopewell was a ranked society with centralized redistribution under the control of big men or chiefs are now considered to be corporate gifts or community-but not personal-valuables (Yerkes 228). Hopewell village sites are ephemeral, while their ceremonial mounds are complex and labor intensive, giving the impression that their domestic activities seem to be consistent with what would be expected in a tribal society, while their level of labor organization and exchange is more like a chiefdom (230). According to Yerkes, neither sedentism nor agriculture was essential for the emergence of tribal-level organization in the southeast. Some general convergences can be noted with the Jomon cases, showing different combinations and degrees of sedentism, cultivation, and social complexity.

Recently, monument building was found to have begun in the southeast region of North America much earlier than Hopewell, and it has raised questions concerning emergent social complexity. The building of monumental mounds of the Shell Mound Archaic Culture in the lower Mississippi began as early as $7400 \mathrm{cal}$ B.P., and mounds in northwestern Louisiana have been dated to 5600 to $5000 \mathrm{cal}$ B.P. (Sassaman 2004:253). Few burials have any grave goods, and those with grave goods do not show consistent patterning by age and sex (257). According to Sassaman, "The populations creating these mounds were mobile, generalized foragers with no overt economic expressions of social differentiation or inequality" (254). It is thought that some architectural features of the mounds may have indicated relative status. Some of the Middle Archaic mounds of southern Louisiana have prior construction that marked their place as well as orientations that suggest that they were aligned to each other, creating "entire landscapes of monumental architecture" (260). Late Archaic period shell ring mounds, which may be associated with feasting or other group ritual activity, are the subject of debate concerning the social complexity of the groups that made them (262).

\section{Factors Related to Social Complexity}

What led to hunting-gathering social complexity? Price and Brown (1985:8) found three common factors among complex hunter-gatherers: societal circumscription, abundant resources, and high population. For a resource to be used as the basis of sedentism and a rank society, it must be abundant and predictable (Matson 1985:246-247). Unless the resource is reliable, it will not permit continuing concentration of ownership by a small group. Testart (1982) identified the storage economy of hunter-gatherers, which is tied to abundance and seasonality of resources and efficient food-getting and storage techniques. He noted that sedentism may bring an increase in material wealth, but it does necessarily do so. Only large-scale storage brings social inequality. Testart found that those hunter-gatherers who practice intensive storage are collectors of aquatic resources; no large-scale storage was practiced by those involved totally in landbased subsistence. 
Is it necessary for hunter-gatherers to supplement their subsistence with some kind of cultivation to achieve complexity? In his review of 94 hunter-gatherer groups from North America and other parts of the world, Keeley (1992:37-38) found that hunter-gatherer social complexity and protoagricultural origins are not necessarily linked. The population threshold for protoagriculture is much lower than that of storage economies, and protoagriculture occurs only in a restricted range of environmental conditions, while storage economies occur over a wide range of latitudes and rainfall patterns.

In his study of 17 categories of ethnographic and environmental data in 339 hunter-gatherer groups, Binford produced dozens of generalizations, many of which are germane to the Jomon case. A few are mentioned here. As population increases, packing leads to competition and a reduction of territory, and communities had to survive by storage or intensification. From the ideas of Matson and Testart, we can see that storage and intensification lead to control of resources and hierarchy. Like Testart, Binford found a "strong association between nonegalitarian social characteristics and the use of aquatic resources" (2001:368). Packing thresholds, which are different for land-based or aquatically based hunter-gatherers or farmers, are important in shifts in social organization and subsistence change. When a packing threshold for land-based hunter-gatherers is reached, group size decreases and there is more emphasis on aquatic resources (if these are available) and on females' contribution to subsistence.

We should expect great variability in responses to packing, given the range of latitude covered by the Japanese islands, the effects of warm and cold ocean currents, and broad distinctions between deciduous and broadleaf forests, the boundaries of which changed over the long duration of the Jomon period.

Binford discusses relationships between storage and intensification. In warm climates, following constriction of territory and packing, people will attempt to intensify the collection of terrestrial plants because aquatic products are difficult to store in areas of high temperatures. In cool temperate and colder climates, they will continue specialization in aquatic species since they can be stored (2001:468). He found that the settlements of land-based hunter-gatherers in his sample increased in size once packing occurred, but aquatically dependent peoples continued to segment. Generally, Sakaguchi (2003:190-191) notes that storage pits for the preservation of sweet chestnut (Castanopsis crenata) were well developed in northeastern Japan, where the average capacity of each pit was 2 to 3 $\mathrm{m}^{3}$. In southwestern Japan, smaller, fewer pits averaged less than $1 \mathrm{~m}^{3}$. Hayashi (1997) found that distinctive storage facilities appear in the Middle to Final stage of Early Jomon (5500-5000 B.P.) and that in the Late Jomon there must have been an abundance of storage to support monument building. At the southern extremity of Jomon Culture, Okinawa $\left(26^{\circ} \mathrm{N}\right)$, storage pits for edible chestnuts (Cyclobalanopsis miyagii) and an associated paved area were found near a seaside freshwater spring at the Maebaru site (China 2000). The deposits are dated roughly between 3000 and 3800 B.C. The nuts, preserved in fresh water, require leaching to render them edible; they have also been found in Later Jomon sites on Okinawa. Perhaps this emphasis on terrestrial resources indicates a trend toward packing on the subtropical Ryukyu Islands.

Binford found changes in exchange at the threshold of packing, from circulation between kin and trading partners to network-based exchanges of reduced 
scale $(2001: 469)$. He found that short-distance family-related trading expeditions were associated with some form of money or production of craft items or primitive valuables. Some of the Jomon ornaments - slit jade earrings, carved clay ear spools, and small, highly decorated pottery vessels-may have been put to this purpose. Kelly noted that under conditions of spatially heterogeneous resource fluctuations, groups responded by creating boundary defenses and gaining access to different groups and resources (1995:309-320). When the subsistence bases of the participants in a network are not all tied to the same source, then risk is reduced by constructing social relationships to ensure access to these craft items or stored food. In conditions of spatially homogeneous resource variability, it will be less possible to reduce risk through social networks; it may be better for each family to build its own store of food, and individual resource ownership may appear. The extension of flame pottery from Niigata into Gumma, on the eastern side of the Japan Alps, may indicate the extension of social relationships to groups relying on different subsistence catchments. A similar situation may have occurred with the spread of pottery types from the Japan Alps to the Kanto region near Tokyo. Yamamoto (2004) describes a case in the early Middle Jomon of central Honshu in which a boundary between the Echigo and Kanto/Chubu regions has been noted in the second of six temporal stages of the Goryogadai pottery type. He used Hodder's study of Baringo, Kenya (1982:31-36), as a model to suggest that in areas of economic competition and stress, boundaries were maintained. This perspective could be broadened to suggest that exchange areas became constricted. Yamamoto noted that within the sites of the Chubu region of Honshu, stylistic subregions emerged. He tied these to changing communication systems, which, I would suggest, are probably linked to different types of resources and to different spheres of production.

The distribution of scarce products such as amber, cinnibar, asphalt, and hard stones may provide important clues as to the regional organization of Jomon communities. Keeley (1996:123) notes that competition over monopolies of particular commodities could lead to warfare. While the prevalence of Jomon warfare remains a topic of debate, Suzuki (1999:42) notes 18 sites in which casualties could be determined from osteological remains and urges archaeologists to look carefully in the future for evidence of trauma. The cases spanned the Jomon period, becoming more frequent in the Final Jomon.

Despite the richness of Jomon archaeological data, it has been difficult to analyze distributions or access to luxury goods. More investigation is needed on Fitzhugh's "variations in quality and quantity of materials across populations" (2003:15). However, individual cases are compatible with a fluid, tribal type of organization. Imamura reached similar conclusions, noting that there were definitely special leaders and important elders, but that the term "kaiso" (class) is a misnomer (2002:71-73). Could it be that the diversity of resources in the Japanese environment, affected by both latitude and elevation coupled with high population and packing, made it difficult for a single group to "own" a resource and intensify its exploitation? Future regional studies that focus on distribution and covariation of luxury items in relation to site and house plan may elucidate these questions. As the pace of state-sponsored resource archaeology slows in Japan, perhaps more emphasis will be placed on digesting the enormous quantities of excavated data and comparing site patterning. 


\section{ACKNOWLEDGMENTS}

I thank Dr. Simon Kaner for lending me the Sasayama and Dokunmae site reports, as well as the International Jomon Culture Conference, Tokyo, for making available research materials and giving me the opportunity to ruminate on this topic. I am most grateful to three anonymous reviewers, and to Professor Laura Junker, who provided extremely valuable comments on the content and organization of this paper. Thanks are offered to the Tokamachi City (Niigata Prefecture) and Shibusawa City (Gumma Prefecture) Boards of Education for permission to include photographs of Jomon pottery from the Sasayama and Dokunmae Sites, respectively.

\section{REFERENCES}

Abe, Chiharu

2001 Saiko no urushi seihin: Jomon jidai soki no haka kara shutsudo (The oldest objects made of lacquer: from a grave of the Initial Jomon period), in Hakkutsu Sareta Nihon Retto 2001 (Excavations in the Japanese Islands 2001): 13, ed. Bunka Cho. Tokyo: Mainichi Shimbunsha.

Aikens, Melvin, And Don Dumond

1986 Convergence and common heritage: Some parallels in the archaeology of Japan and northwestern North America, in Windows on the Japanese Past: Studies in Archaeology and Prehistory: 163-178, ed. R. Pearson, G. Barnes, and K. Hutterer. Ann Arbor: University of Michigan Center for Japanese Studies.

ARNOLD, JEANNE

2001 The Origins of a Pacific Coast Chiefdom: The Chumash of the Channel Islands. Salt Lake City: University of Utah Press.

BINFORD, LEWIS

2001 Constructing Frames of Reference: An Analytical Method for Archaeological Theory Building Using Hunter Gatherer and Environmental Data Sets. Berkeley: University of California Press.

\section{Chiba, Toshiro}

2000 Seiko no urushi no gijutsu o kushi kazari yumi 10 ten ga ikyo shutsudo (Exquisite lacquer technique used freely; ten decorated bows found together), in Hakkutsu Sareta Nihon Retto 2000 (Excavations in the Japanese Islands 2000): 30, ed. Bunka Cho. Tokyo: Mainichi Shimbunsha.

China, Teiji

2000 Maebaru iseki no mizuba iko to chozo ketsu (The washing area and storage pits of the Maebaru site). Kikan Kokogaku 73:23-26.

Dettler, Michael, and Brian Hayden

2001 Digesting the feast, in Feasts: Archaeological Perspectives on Food, Politics and Power: 1-22, ed. Michael Dietler and Brian Hayden. Washington, DC: Smithsonian Institution.

EARLe, Timothy

2004 Culture matters in the Neolithic transition and emergence of hierarchy in Thy, Denmark: Distinguished lecture. American Anthropologist 106(1):111-125.

Ebihara, Kunio

2003 Kita Kanto, Niigata, Minami Tohoku no Jomon doki ga sorotte shutsudo (The finding together of Jomon pots from northern Kanto, Niigata, and southern Tohoku), in Hakkutsu Sareta Nihon Retto 2003 (Excavations in the Japanese Islands 2003): 19, ed. Bunka Cho. Tokyo: Mainichi Shimbunsha.

Fitzhugh, Ben

2003 The evolution of complex hunter-gatherers on the Kodiak Archipelago, in HunterGatherers of the North Pacific Rim: 13-48, ed. J. Habu, J. Savelle, S., Koyama, and H. Hongo. Senri Ethnological Studies 63. Senri: National Museum of Ethnology.

Fowles, SEVERIN

2002 Social type to social process, in The Archaeology of Tribal Societies: 13-33, ed. W. Parkinson. International Monographs in Prehistory, Archaeological Series 15. Ann Arbor: University of Michigan. 


\section{Fried, MORTON}

1975 The Notion of Tribe. Menlo Park, CA: Cummings.

FujImURA, Haruo

1983 Jomon doki sosei ron (Discussion of the composition of Jomon pottery assemblages), in Jomon Bunka no Kenkyu (The Study of Jomon Culture), vol. 5:237-250, ed. Shimpei Kato, Tatsuo Kobayashi, and Tsuyoshi Fujimoto. Tokyo: Yuzankaku Shuppan.

1999 Sosei ron: Obora shiki doki (Discussion of pottery assemblage: Obora type pottery), in Jomon Shiki Doki no Hennen to Shakai (Chronology and Society of Jomon Pottery): 3437, ed. Tatsuo Kobayashi. Tokyo: Yuzankaku Shuppan.

Fujita, Fujio

1999 Jomon shaku wa naze tsukawareta ka (Why was the Jomon foot used?), in Saishin Jomongaku no Sekai (The Most Recent World of Jomon Studies): 104-111, ed. Tatsuo Kobayashi. Tokyo: Asahi Shimbunsha.

Gianno, Rosemary

1990 Semelai Culture and Resin Technology. New Haven: Connecticut Academy of Arts and Sciences.

HABU, JUNKO

2002 Sannai Maruyama iseki no life history: Iseki no kino, teijudo, bunka keikan no hensen (A life history of the Sannai Maruyama site: Changes in site function, residential mobility, and cultural landscape), in Senshi Shuryo-Saishu Bunka Kenkyu no Atarashii Shiya (New Views on Prehistoric Hunter-Gatherer Cultures): 161-183, ed. S. Sasaki. Senri Ethnological Reports 3. Osaka: National Museum of Ethnology.

2004 Ancient Jomon of Japan. Cambridge: Cambridge University Press.

Habu, Junko, and Mark Hall

1999 Jomon pottery production in central Japan. Asian Perspectives 38(1): 90-110.

2001 Jomon pottery production at Honmura-cho and Isarago sites: Insights from geochemistry. Anthropological Science 109(2): 141-166.

Harunari, Hideji, and Mineo Imamura, eds.

2004 Yayoi Jidai no Jitsu Nendai (The True Age of the Yayoi Period). Tokyo: Gakuseisha.

HAYASHI, KeNSAKU

1997 Jomon shakai no shigen riyo, tochi riyo (Resource and land use in Jomon society). Kokogaku Kenkyu 44:35-51.

HAYDEN, BRIAN

1995 Pathways to power: Principles for creating socioeconomic inequalities, in Foundations of Social Inequality: 15-85, ed. T. D. Price and G. Feinman. New York: Plenum Press.

1997 The Pit Houses of Keatley Creek: Complex Hunter Gatherers of the Northwest Plateau. Fort Worth, TX: Harcourt Brace.

2001 Fabulous feasts: A prolegomenon to the importance of feasting, in Feasts: Archaeological Perspectives on Food, Politics and Power: 23-64, ed. Michael Dietler and Brian Hayden. Washington, DC: Smithsonian Institution.

HODDER, IAN

1982 Symbols in Action. Cambridge: Cambridge University Press.

Hokkitsu Mura Kyoiku Iinkai

2001 Dokunmae Iseki (The Dokunmae site). Hokkitsu Mura, Japan: Hokkitsu Mura Kyoiku linkai.

HudSON, MARK

1997 Noko o kobanda Jomonjin (The Jomon peoples' rejection of agriculture). Nihonjin to Nihon Bunka (Interdisciplinary Study on the Origins of Japanese Peoples and Cultures Newsletter) $2: 19$.

IIzUKa, Toshio

2000 Jomon Urushi no Sekai (The World of Jomon Lacquer). Tokyo: Aoki Shoten.

\section{IKAWA-SMITH, Fumiko}

1992 Kanjodori: Communal cemeteries of the Late Jomon in Hokkaido, in Pacific Northeast Asia in Prehistory: Hunter-Gatherers, Farmers, and Political Elites: 83-89, ed. C. M. Aikens and S. N. Rhee. Pullman: Washington State University Press.

\section{IKEDA, KOICHI}

2000 Maiso ni tomonau sekisei soshingurui (Types of stone ornaments found in burials). Kokogaku Janaru 466:4-7. 
IMAMURA, KEIJI

1996 Prehistoric Japan. Honolulu: University of Hawai'i Press.

2002 Jomon no Yutaka to Genkai (Jomon Abundance and Its Limits). Tokyo: Yamakawa Shuppansha.

ITO, TAKASHI

2002a Niigata ken Kurokawa mura Wakeyachi A iseki no chosa ni tsuite (Investigations of the Wakeyachi A site, Kurokawa mura, Niigata Prefecture). Kokogaku Janaru 489:28-31.

2002 b Jomon shikki no yuhin sokkuri iroazayaka ni (Superior Jomon lacquer goods with brilliant color), in Hakkutsu Sareta Nihon Retto 2002 (Excavations in the Japanese Islands 2002): 23, ed. Bunka cho. Tokyo: Mainichi Shimbunsha.

KANEKo, HiROYUKI

1999 Sosei ron: Angyo shiki doki (Angyo-type pottery: Discussion of composition), in Jomon Shiki Doki no Hennen to Shakai (The Chronology and Society of Jomon Pottery): 30-33, ed. Tatsuo Kobayashi. Tokyo: Yuzankaku Shuppan.

KeEley, Lawrence

1992 The use of plant foods among hunter-gatherers: A cross cultural survey, in Prehistoire de l'Agriculture: Nouvelles Approches, Experimentales et Ethnographiques: 9-38, ed. P. Anderson. Paris: Centre national de la recherche scientifique.

1996 War Before Civilization. New York: Oxford University Press.

KeEley, Lawrence, and Daniel Cahen

1989 Early Neolithic forts and villages in NE Belgium: A preliminary report. Journal of Field Archaeology 16(2): 157-176.

KELLY, ROBERT

1992 Mobility/sedentism: Concepts, archaeological measures, and effects. Annual Review of Anthropology $21: 43-66$.

1995 The Foraging Spectrum: Diversity in Hunter Gatherer Lifeways. Washington, DC: Smithsonian Institution Press.

Kenjo, Toshiko

1983 Shikko (Lacquer craft), in Jomon Bunka no Kenkyu (The Study of Jomon Culture), vol. 7:286-292, ed. Shimpei Kato, Tatsuo Kobayashi, and Tsuyoshi Fujimoto. Tokyo: Yuzankaku Shuppan.

\section{Kobayashi, Tatsuo}

1974 Behavioral patterns reflected in pottery remains: The Jomon period. Arctic Anthropology $11: 163-170$.

Kobayashi, TATSUO, eD.

2002 Jomon Randosceipu (Jomon Landscape). Tokyo: Jomonesk Japan.

Koyama, Shuzo, and David Thomas, eds.

1981 Affluent Foragers: Pacific Coasts East and West. Senri Ethnological Studies No. 9. Osaka: National Museum of Ethnology.

Kujit, Ian, and Nigel Goring-Morris

2002 Foraging, farming, and social complexity in the Pre-Pottery Neolithic of the Southern Levant: A review and synthesis. Journal of World Prehistory 16(4):361-440.

MARQUARDT, William

1985 Complexity and scale in the study of fisher-gatherer-hunters: An example from the eastern United States, in Prehistoric Hunter Gatherers: The Emergence of Cultural Complexity: 59-98, ed. D. Price and J. Brown. New York: Academic Press.

Matson, Richard

1985 The relationship between sedentism and status inequalities among hunters and gatherers, in Status, Structure, and Stratification: Current Archaeological Reconstructions: 245-252, ed. M. Thompson, M. Garcia, and F. Kense. Calgary, Canada: University of Calgary Archaeological Association.

Matsui, Akira, and Masa'aki Kanehara

2006 The question of prehistoric plant husbandry during the Jomon period in Japan. World Archaeology' 38(2):259-273.

Miura, Masato

2002 Jomon-Satsumonki no Hokkaido ni okeru shikki kohin no doko (Trends in lacquerware in the Jomon to Satsumon periods of Hokkaido). Kokogaku Janaru 488:7-11. 


\section{Mizoguchi, KoJI}

2002 An Archaeological History of Japan 30,000 B.C. to A.D. 700. Philadelphia: University of Pennsylvania Press.

MORI, KOICHI

1989 Ki to Tsuchi to Ishi no Bunka: Kyusekki Jidai-Jomon Jidai Koki (Culture of Wood, Earth, and Stone: From the Palaeolithic to Late Jomon). Tokyo: Chuo Koron.

NaKamura, OKI

2000 Saishu shuryomin no fukuso koi (Practices of offering grave goods of hunter-gatherers). Kikan Kokogaku 70:19-23.

2002 Kaiso shakai (Social ranking). Kikan Kokogaku 80:38-41.

Niigata Ken Tokamachi Shi Kyoiku Iinkai

1998 Sasayama Iseki Hakkutsu Chosa Hokoku (Excavation Report of the Sasayama Site). Tokamachi, Japan: Tokamachi Shi Kyoiku Iinkai.

OKAMURA, Michio

2002 Jomon no Seikatsu Shi (Records of Jomon Life). Tokyo: Kodansha.

OTAHARA, JUN

2000 Sannai Maruyama iseki no ropponbashira kyobokujuretsu to nishitsu nifun (The alignment of six large wooden posts at the Sannai Maruyama site and the solstice and equinox). Jomon Jidai $11: 103-135$.

Parkinson, William

2002 Introduction: Archaeology and tribal societies, in The Archaeology of Tribal Societies: 1-12, ed. W. Parkinson. International Monographs in Prehistory, Archaeological Series 15. Ann Arbor: University of Michigan.

Pearson, Richard

2004 New perspectives on Jomon society. Bulletin of the International Jomon Culture Conference $1: 63-71$.

2005 The social context of early pottery in the Lingnan region of South China. Antiquity $79: 819-828$.

2006 Jomon hot spot: Increasing sedentism in southwestern Japan in the Incipient Jomon (14,000-9250 cal B.C.) and Earliest Jomon (9250-5300 cal B.c.). World Archaeology $38(2): 239-258$.

Price, T. Douglas

1995 Social inequality at the origins of agriculture, in Foundations of Social Inequality: 129-154, ed. T. D. Price and G. Feinman. New York: Plenum Press.

2002 Afterword: Beyond foraging and collecting: Retrospect and prospect, in Beyond Foraging and Collecting: Evolutionary Change in Hunter-Gatherer Settlement Systems: 413-425, ed. B. Fitzhugh and J. Habu. New York: Kluwer Academic/Plenum.

Price, T. Douglas, and James A. Brown

1985 Aspects of hunter-gatherer complexity, in Prehistoric Hunter-Gatherers: The Emergence of Cultural Complexity: 3-20, ed T. Douglas Price and James Brown. Orlando, CA: Academic Press.

Rowley-Conwy, Peter

2002 Time, change, and the archaeology of hunter gatherers: How original is the "Original Affluent Society"?, in Hunter-Gatherers: An Interdisciplinary Perspective: 39-72, ed. C. Panter-Brick, R. Layton, and P. Rowley-Conwy. Cambridge: Cambridge University Press.

Sakaguchi, Takashi

2003 Jomon Jidai Chozoketsu no Kenkyu (Study of Jomon Storage Pits). Tokyo: Amu Promotion.

SASAKI, Fujio

2002 Kanjo resseki to Jomonshiki kaiso shakai (Stone circles and Jomon-type stratified society), in Jomon Shakai Ron (Discussion of Jomon Society), vol. 2:3-50, ed. Masahito Anzai. Tokyo: Doseisha.

SASAKI, KOMEI

1997 Nihon Bunka no Tashu Kozo (The Multiple Structure of Japanese Culture). Tokyo: Shogakkan.

Sassaman, Kenneth

2004 Complex hunter-gatherers in evolution and history: A North American perspective. Journal of Archaeological Research 12(3):227-280. 
SHINTO, KoICHI

2001 Nihon bunka no hikari wa Kyushu kara (The light of Jomon Culture from southern Kyushu), in Saishin Jomongaku no Sekai (The Most Recent World of Jomon Studies): 112-120, ed. Tatsuo Kobayashi. Tokyo: Mainichi Shimbunsha.

STARgARDT, JANET

2000 Behind the shadows: Archaeological data on two-way sea-trade between Quanzhou and Satingpra, south Thailand, 10th-14th century, in The Emporium of the World, Maritime Quanzhou, 1000-1400: 309-394, ed. A. Schottenhammer. Leiden: Brill.

Stuiver, M., P. Reimer, E. Bard, J. Beck, G. Burr, K. Hughen, B. Kromer, G. McCormac, J. van der Plicht, and M. Spurk

1998 INTCAL 98 radiocarbon age determination, 24,000-0 cal BP. Radiocarbon 40(3):10411083.

Suzuki, TAKaO

1999 Honto ni nakatta no ka? Jomon jin no shudanteki tatakai (Was it definitely absent? Jomon group warfare), in Saishin Jomongaku no Sekai (The Most Recent World of Jomon Studies): 36-47, ed. Tatsuo Kobayashi. Tokyo: Asahi Shimbunsha.

TAKAHASHI, RyuZaBuro

2001 Soron: Sonraku to shakai no kokogaku (General remarks: The archaeology of settlement and society), in Sonraku to Shakai no Kokogaku (Archaeology of Settlement and Society), ed. Ryuzaburo Takahashi: 1-93. Vol. 6 of Gendai no Kokogaku (Contemporary Archaeology [series]), general ed. Takuya Iwasaki. Tokyo: Asakura Shoten.

TANiguChI, YASUHIRO

2001 Jomon jidai no iseki no nendai (Chronology of sites of the Jomon period). Kikan Kokogaku 77:17-21.

Testart, Alain

1982 The significance of storage among hunter-gatherers: Residence patterns, population densities, and social inequalities. Current Anthropology 23(5):523-537.

Tsuboi, Mutsumi

2001 Kakinoshima B iseki no urushi seihin (Lacquer objects from the Kakinoshima B site). Kokogaku Janaru 479:26-29.

UEDA, MAKOTO

1999 Sosei ron: Katsusaka shiki doki (Discussion of pottery assemblages: Katsusaka-type pottery), in Jomon Shiki Doki no Hennen to Shakai (Chronology and Society of Jomon Pottery): 26-29, ed. Tatsuo Kobayashi. Tokyo: Yuzankaku Shuppan.

UWAYA, SHIN'ICHI

2000 Karimba 3 iseki: Hokkaido Eniwa shi (The Karimba 3 site: Eniwa City, Hokkaido), in Hakkutsu Sareta Nihon Retto 2000: 28-29, ed. Bunka cho. Tokyo: Mainichi Shimbunsha.

UWAYA, SHIN'ICHI, AND IKUKo SATO

2000a Nihon no iseki; Hokkaido Karimba dai 3 iseki (Sites in Japan: The Karimba No. 3 site). Kokogaku Kenkyu 46:4:136-138.

2000b Eniwa shi Karimba 3 iseki no soshingu (Ornaments from the Karimba No. 3 site, Eniwa City). Kokogaku Janaru 466:17-20.

WatANABE, Hitoshi

1990 Jomonshiki Kaiso Shakai (Jomon-Type Stratified Society). Tokyo: Rokko Shuppan.

Weissner, Polly

2001 Feasting and value: Enga feasts in historical perspective (Papua New Guinea), in Feasts: Archaeological Perspectives on Food, Politics, and Power: 115-143, ed. Michael Deitler and Brian Hayden. Washington, DC: Smithsonian Institution.

YAMAMOTO, NoRIYUKI

2004 The life structure of the Jomon period: Earliest Middle Jomon. Bulletin of the International Jomon Culture Conference 1:79-89.

Yamanashi Kenritsu Hakubutsukan

2002 Waza to Bi no Tanjo (The Birth of Craft and Beauty). Yamanashi, Japan: Yamanashi Kenritsu Hakubutsukan.

YERKES, RICHARD

2002 Hopewell tribes: A study of Middle Woodland social organization in the Ohio Valley, in The Archaeology of Tribal Societies. International Monographs in Prehistory, Archaeological Series 15:227-245, ed. W. Parkinson. Ann Arbor: University of Michigan Museum of Anthropology. 


\begin{abstract}
People of the Jomon period (currently dated from about 14,000 B.C. to the first millennium B.C.) began to make lacquer ornaments as early as 7000 B.C. and by the fourth millennium B.C. were creating elaborately decorated, low-fired pottery vessels that appear to have been used for feasting. In the Final period of the Jomon, grave goods appear in a substantial percentage of burials. Without reliance on agriculture, Jomon people appear to have achieved a high level of social complexity. However, the evidence from a few case studies concerning lacquer, elaborate pottery, and burials seems to show that while part-time specialization provided a wealth of rich material culture, sustained hierarchy was not achieved and there was an emphasis on exchange and solidarity, as in other middle-range societies. This article reviews new material and debates. KEYwORDs: Jomon, Japan, social complexity, lacquer, ceramics, burials, craft production, complex hunter-gatherers.
\end{abstract}

